\title{
DE REPENTE, TÃO DE REPENTE... AULAS ONLINE EM TEMPOS DE PANDEMIA: IMPLICAÇÕES NA AUTOFORMAÇÃO, NO PLANEJAMENTO DIDÁTICO E NA AÇÃO DOCENTE
}

\author{
Manoela Oliveira de Souza Santana \\ Universidade Federal da Bahia (UFBA), Salvador, Bahia, Brasil
}

\begin{abstract}
Resumo: O presente ensaio é uma proposta de leitura dialógica, interativa e hipertextual a fim de aprofundar referências que estão no cerne da atuação docente, em especial, no contexto das aulas online, o que requer atenção aos vínculos socioemocionais com as práticas educativas e às inquietações que suscitam planejamentos cuidadosos e novos encaminhamentos pedagógicos, fortalecidos pelo movimento decolonial, enquanto investimentos na educação pública democrática. Para tanto, faz-se mister ter a tecnologia digital como aliada para o pensar e agir nos cenários educacionais, e como alicerce o webcurrículo, bem como a Base Nacional Comum Curricular, em especial, as competências gerais: comunicação e cultura digital. O engajamento na autoformação e na formação docente é imprescindível nesse cenário, pois saberes e fazeres docentes carecem de qualificação para se efetivar a pretensa educação equitativa.
\end{abstract}

Palavras-chave: Aulas Online. Planejamento. Formação Docente.

\begin{abstract}
Um convite para o leitor: Vamos partilhar leituras construindo e recepcionando o sentido deste texto? Para tanto, há um convite com questões diretas em todo o texto e expressóes destacadas em itálico que, talvez, requeiram algumas pesquisas com o suporte das notas. Conto com as suas inferências, sugestões, opinióes e leituras elucidativas por meio de interações com outros textos. Esta produção leitora é, portanto, dialógica e colaborativa. Fique à vontade. Este texto é nosso!
\end{abstract}

De repente, tão de repente, em nossas implicações educacionais, em meio à pandemia, ${ }^{1}$ precisamos repensar e nos reinventar na condição de docentes. Provisoriamente, não podemos alimentar a rotina de ir para a escola, ver os(as) nossos(as) alunos(as), encontrar os nossos(as) colegas, saudar o(a) porteiro(a), o(a) tio(a) da merenda e o(a) que mantém a escola limpa. E o que mais, amigo(a) leitor(a)? As distâncias físicas foram sendo marcadas em nossas interações. Têm sido crescentes a saudade e a preocupação em nos aproximarmos, em termos humanos e pedagógicos, daqueles que são o sentido maior do espaço escolar.

E, agora, o que nos aguarda como profissionais que passamos a ter, como maior possibilidade de materializar essa aproximação, o uso de artefatos tecnológicos digitais 
e vermos, diante do (im)possível e do necessário, se instaurar um novo referencial para as nossas atividades? ${ }^{2}$

Certamente, a construção de um novo anormal. ${ }^{3}$ Isso mesmo: a $\mathrm{n}$ o $\mathrm{r}$ m a I!!! Antes de sermos desafiados a vivenciar a experiência atual, as relações na escola estavam sendo convidadas a tomar novos rumos sem replicar uma modernidade por meio de uma pós-modernidade tão mascarada pelo neoliberalismo segregador. ${ }^{4}$ Dizemos isso pois o convite é para entendermos e empreendermos ações e reflexões sobre a construção da aprendizagem, afirmando todos engajados no processo educacional. Não se trata de negar um para afirmar o outro, mas nos termos como humanos, com direitos iguais e responsabilidades, numa mesma intensidade e cadência, em favor da oferta equitativa e qualitativa da educação.

Nesse sentido, num tom de desequilíbrio, de inquietações, de desconfiança, precisamos ter, também como protagonistas do processo educacional, "as vozes do sul" ${ }^{5}$ somadas a outras vozes que a decolonialidade nos impele, ${ }^{6} \mathrm{e}$ entender que são possíveis novas condições de alimentação, cuidados com a saúde, amizade, diversão, estudo e trabalho. Até dizem que é chegada a hora de o Século XXI, finalmente e de fato, se iniciar. Concorda, caro(a) leitor(a)?

Nesse ínterim, as relações com a tecnologia digital nos requisitam, com mais força, para sermos-tecnologicamente-no-mundo. ${ }^{7}$ Aqui, destaco que a tecnologia não é um artefato à parte. É a pele de nossa cultura. É peculiar a este momento entender o pensamento computacional sem perder de vista as relações éticas, a sensibilidade, as culturas híbridas e os poderes oblíquos. ${ }^{8}$ Não é isso, leitor(a) parceiro(a)?

O webcurrículo tem um grande espaço nesse cenário, ${ }^{9}$ pois se atualiza e se contextualiza como um dos caminhos a ser percorrido no bosque da educação, ${ }^{10}$ já que se materializa por meio das tecnologias digitais de informação e comunicação, e também é mediado pela internet, a fim de propiciar o aprendizado de conhecimentos científicos, sociais, éticos, morais, espirituais, afetivos e culturais, com base naquilo que o estudante já traz de sua experiência. $\mathrm{O}$ uso do webcurrículo, mais precisamente, implica apropriar-se dessas tecnologias em prol da interação, do trabalho colaborativo e do protagonismo entre todas as pessoas para o desenvolvimento do currículo. Qual a sua apreciação sobre webcurrículo?

Integram-se à vivência de um webcurrículo os diálogos com as competências socioemocionais e, em especial, com duas outras competências gerais (Comunicação $e$ Cultura Digitah) ${ }^{11}$, às quais estamos aliados e alinhados, considerando que lidar consigo, com o outro e com as demandas da vida nos movem em nossas atividades e precisamos, essencialmente, de comunicação, bem como da cultura digital.

Dependemos da Comunicação, dada a necessidade de utilizar diferentes linguagens - verbal (oral ou visual-motora, como Libras, e escrita), corporal, visual, sonora e digital -, bem como dos conhecimentos das linguagens artística, matemática e científica para se expressar e partilhar informações, experiências, ideias e sentimentos em variados contextos e produzir sentidos para o entendimento mútuo.

Necessitamos da Cultura Digital mediante a relevância de se compreender, utilizar e criar tecnologias digitais de informação e comunicação de forma crítica, significativa, reflexiva e ética nas diversas práticas sociais (incluindo as escolares) para se 
SANTANA, M. O. de S

comunicar, acessar e disseminar informações, produzir conhecimentos, resolver problemas e exercer protagonismo e autoria na vida pessoal e coletiva. Você já tinha feito uma leitura atenta das Competências Gerais 4 e 5 da BNCC?

Então, com a minha autonomia, responsabilidade docente e criatividade, não me furto de entrar em meu atalho desse bosque e, assim, prover, na condição de atora e autora, ações pedagógicas numa relação tempo/espaço peculiares à cibercultura. ${ }^{12}$ Quando falamos em tempo, não podemos esquecer das relações síncronas e assíncronas. As primeiras dizem respeito às interações entre os envolvidos no processo educacional em um tempo presente. As segundas mantêm viva a possibilidade de interatividade, sem vivenciarmos um diálogo online. Entendemos o que são relações síncronas e assíncronas peculiares ao contexto da cibercultura?

Sobre o espaço, aqui referencio o ambiente virtual e o ambiente digital, ${ }^{13}$ entendendo que o virtual (o que é feito e simulado por meios eletrônicos) e o digital (possibilidade de traduzir as informações em números, para que possam ser armazenadas, transmitidas, copiadas e retraduzidas) são mecanismos que integram as plataformas materializadas pelos recursos da internet, que poderão ter vida no campo, na cidade, na sala, na cozinha, no quintal, ou seja, onde for possível se conectar à aprendizagem. Está me acompanhando, leitor(a)? O que mais referencia esse ambiente?

Gosto muito de falar em sincronia, em interação, em ambiência online, em rede, pois o cheiro do humano bem vivaz nos alimenta em atividades educacionais autorais, interativas e colaborativas. Já não soa muito bem para mim as expressões remoto, à distância, pois me remetem à ausência, à perda, à mecanização e à lógica determinista da mera transmissão de informação ou de um humanismo espontaneísta. Um alerta: cuidado com a live, com as proposições de atividades no Google Sala de Aula, com a videoaula gravada e tudo mais em que só um monopoliza a fala, a imagem, os registros, num processo que não faz sentido sem o humano. Nada contra o uso dessas ferramentas, desde quando se promovam autoria, interatividade e colaboração no processo ensino e aprendizagem. Quais as suas impressões sobre o tempo nas práticas pedagógicas?

Então, de repente, tão de repente, cultivemos a sincronia e, certamente, numa movência interativa, orquestrada e como uma das felicidades certas, poderemos contemplar escolas e famílias viverem o tão citado e sonhado estreitamento de laços. Neste instante, atentos para algo interessante: o quê os cursos de formação inicial e continuada não conseguiram implementar, a autoformação tem permitido, como uma das forças do processo formacional do professor na perspectiva da profissionalidade docente. ${ }^{14}$ Aqui, referenciamos a formação docente sociotécnica, ética, estética e política. E você, como tem alimentado sua (auto)formação profissional neste momento?

É muito bom saber que: há famílias reconhecendo todo empenho da equipe escolar; os estudantes esperam o horário para ver o professor, sentir um pouco os colegas com os quais o contato foi tão pequeno no início deste ano letivo; adolescentes estão alimentando a dialogicidade e se sentindo menos isolados; há professor dizendo que, após este momento, vai ser repórter, youtuber, depois de, como sempre, ter dado o melhor pela causa educacional. Tudo isso tem uma energia magnífica que só quem ama e cuida do educar pode experimentar e entender. 
Num tom pessoal e profissional, posso dizer com muita força:

- O professor é um mediador tão importante...

- Não temos só os livros ou as apostilas impressas como recursos didáticos...

- A avaliação pode qualificar o meu trabalho e o crescimento do estudante, sendo inclusiva...

- Metodologia ativa é possível, ${ }^{15} \mathrm{meu} / \mathrm{minha}$ aluno(a) é protagonista de sua aprendizagem...

- Estamos experimentando mais amor, empatia e altruísmo nas interações pedagógicas...

E você pode dizer o quê?

E de repente, tão de repente, experiências de autoformação, de práticas de aulas não presenciais me ajudam a construir um encontro mais harmônico comigo, com o estudante, com a família, com outros docentes, entre outros atores e autores do processo educacional. Na feitura cotidiana, são os novos jeitos de encontrar, estudar, comungar, dialogar, ouvir, ver, amar, conhecer, abraçar que nos permitem (re)existir, em uma espera, tão esperançosa, de dias vindouros mais seguros. De repente, tão de repente... Fique à vontade para, por ora, dar a palavra final, caro(a) leitor(a)...

Ensaio recebido em: 20/08/2020

Aprovado para publicação em: 30/12/2020

\section{NOTAS}

1 - ORGANIZAÇÃO Mundial de Saúde declara pandemia do novo Coronavírus. UNA-SUS, Brasília, 11 mar. 2020. Disponível em: https://www.unasus.gov.br/noticia/organizacao-mundial-de-saudedeclara-pandemia-de-coronavirus. Acesso em: 20 de mar. 2020.

2 - Reflexão suscitada pela leitura de DERRIDA, Jacques. A escritura e a diferença. Tradução: Maria Beatriz Marques Nizza da Silva, Pedro Leite Lopes e Pérola de Carvalho. São Paulo: Perspectiva, 2014.

3 - Expressão utilizada por Nelson Pretto em entrevista sistematizada em: ARAÚJO, J.; LYRA, O. Nelson Pretto diz que a educação remota não substitui importância da escola na formação dos alunos. Muita Informação, Salvador, 11 maio 2020. Disponível em https://muitainformacao.com.br/post/9531-nelson-pretto-diz-que-a-educacao-remota-naosubstitui-importancia-da-escola-na-formacao-dos-alunos--. Acesso em: 11 maio 2020.

4 - Sobre o neoliberarismo, buscou-se referenciais em: DUMÉNIL, G.; LÉVY, D. A crise do neoliberalismo. São Paulo: Boitempo, 2014.

5 - Para pensar sobre "as vozes do sul", tomou-se como base: MOITA LOPES, L.P. Linguística Aplicada e Vida Contemporânea: Problematização dos Construtos que Têm Orientado a Pesquisa. In: MOITA LOPES, L. P. Por uma Linguística Aplicada Indisciplinar. São Paulo: Editora Parábola, 2006. p. 85-107.

6 - Uma grande contribuição para se discutir os reflexos da decolonialidade está em: SANTOS, Boaventura de Sousa; MENESES, Maria Paula. (orgs.) Epistemologias do Sul. São Paulo; Editora Cortez. 2010. 
SANTANA, M. O. de S.

7 - Refinar a compreensão sobre a expressão "ser-tecnologicamente-no-mundo" em CUPANI. A. Filosofia da Tecnologia: um convite. 3. ed. Florianópolis: Editora da UFSC, 2016.

8 - Ver as considerações sobre "Cultura oblíqua e poderes oblíquos" em CANCLINI, Néstor García. Culturas Hibridas - estratégias para entrar e sair da modernidade. Tradução de Ana Regina Lessa e Heloísa Pezza Cintrão. São Paulo: EDUSP, 1997.

9 - Pode-se aprofundar a compreensão sobre Webcurrículo em: ALMEIDA, Maria Elizabete Biancocini; ALVES, Dom Robson Medeiros; OSB e LEMOS, Silvana Donadio Vilela. Web currículo (recurso eletrônico). Aprendizagem, recurso e conhecimento com o uso de tecnologias digitais. Rio de Janeiro: Letra Capital, 2014.

10 - Fez-se aqui uma alusão a bosque a partir da leitura de ECO. Umberto. Seis Passeios pelo Bosque. São Paulo: Companhia das Letras, 1994.

11 - Para esta produção, foi utilizada a versão da Base Nacional Comum Curricular (BNCC) para o Ensino Médio, instituída pela Resolução n 4, de 17 de dezembro de 2018.

12 - Conferir a abordagem sobre cibercultura em LÉVY, Pierre. Cibercultura. Tradução: Carlos Irineu da Costa. São Paulo: Editora 34, 2000.

13 - Sugerimos ampliar as discussões sobre ambiente virtual e ambiente digital em SANTOS. Edméa Oliveira. Ambientes virtuais de aprendizagem: por autorias livre, plurais e gratuitas. In: Revista FAEBA, Salvador-BA, v. 12, n. 18, p. 5-25, 2003.

14 - Convida-se para o refinar do conhecimento sobre o processo formacional docente em: SCHÖN, Donald. Formar professores como profissionais reflexivos. Im. NÓVOA, Antônio (org.). Os professores e sua formação. Lisboa: Publicações Dom Quixote, 1992. p. 79-107.

15 - Kim, L. M. V. Metodologias ativas de ensino. coconstrução subjetiva da capacidade de pensar o próprio pensamento em sala de aula. Rev. Bras. Psicodrama, São Paulo, v. 26, n. 1, p. 31-40, 2018.

ALL OF A SUDDEN, SO SUDDENLY... ONLINE CLASSES IN TIMES OF PANDEMIC: IMPLICATIONS IN SELF-FORMATION, IN DIDACTIC PLANNING AND TEACHING ACTION

ABSTRACT: The present essay is a proposal for a dialogical, interactive and hypertextual reading, in order to deepen references which are in the heart of teaching activities, especially in the context of online classes, which requires attention to socio-emotional ties with educational practices and concerns that require careful planning and new pedagogical approaches, strengthened by the decolonial movement, as investments on democratic public education. To this end it is essential to have digital technology as an ally for thinking and acting in educational settings and as a foundation for the web curriculum, as well as the Common National Curriculum Base in particular these general skills: communication and digital culture. Engaging in self-training and teacher training is essential in this scenario knowledge and skills of teachers need qualification to carry out that supposed equitable education.

KEYWORDS: Online Classes. Planning. Teacher Education.

DE REPENTE, TAN DE REPENTE... CLASES ONLINE EN TIEMPOS DE PANDEMIA: IMPLICACIONES EN LA AUTO-FORMACIÓN, EN LA PLANIFICACIÓN DIDÁCTICA Y LA ACCIÓN DOCENTE

RESUMEN: Este ensayo es una propuesta de lectura dialógica, interactiva e hipertextual, con el fin de profundizar referentes que están en el corazón de las actividades docentes, especialmente en 
el contexto de las clases online, lo que requiere atención a los vínculos socioemocionales con las prácticas e inquietudes educativas que requieren una planificación cuidadosa y nuevos enfoques pedagógicos, fortalecidos por el movimiento descolonial, al mismo tiempo que se invierte en una educación pública democrática. Para ello, es fundamental contar con la tecnología digital como aliado para pensar y actuar en entornos educativos y como fundamento del currículo web, así como de la Base Curricular Nacional Común, en particular, las competencias generales: comunicación y cultura digital. Participar en la autoformación y formación docente es fundamental en este escenario, ya que los conocimientos y habilidades de los docentes carecen de la calificación para llevar a cabo la supuesta educación equitativa.

PALABRAS CLAVE: Clases Online. Planificación. Educación del Profesorado.

\section{REFERÊNCIAS}

ALMEIDA, M. E. B; ALVES, D. R. M.; OSB e LEMOS, S. D. V. Web currículo (recurso eletrônico). Aprendizagem, recurso e conhecimento com o uso de tecnologias digitais. Rio de Janeiro: Letra Capital, 2014.

ARAÚJO, J.; LYRA, O. Nelson Pretto diz que a educação remota não substitui importância da escola na formação dos alunos. Muita Informação, Salvador, 11 maio 2020. Disponível em: https://muitainformacao.com.br/post/9531-nelson-pretto-diz-que-aeducacao-remota-nao-substitui-importancia-da-escola-na-formacao-dos-alunos--. Acesso em: 11 maio 2020.

BRASIL, 2017. Ministério da Educação. Base Nacional Comum Curricular. Brasília, 2018. Disponível em: http://basenacionalcomum.mec.gov.br/wpcontent/uploads/2018/02/bncc-20dez-site.pdf. Acesso em: 30 abr. 2020.

CANCLINI, N. G. Culturas Híbridas - estratégias para entrar e sair da modernidade. Tradução de Ana Regina Lessa e Heloísa Pezza Cintrão. São Paulo: EDUSP, 1997.

CUPANI. A. Filosofia da Tecnologia: um convite. 3. ed. Florianópolis: Editora da UFSC, 2016.

DERRIDA, J. A escritura e a diferença. Tradução: Maria Beatriz Marques Nizza da Silva, Pedro Leite Lopes e Pérola de Carvalho. São Paulo: Perspectiva, 2014.

DUMÉNIL, G.; LÉVY, D. A crise do neoliberalismo. São Paulo: Boitempo, 2014.

ECO. Umberto. Seis Passeios pelo Bosque. São Paulo: Companhia das Letras, 1994. 
SANTANA, M. O. de S.

KIM, L. M. V. Metodologias ativas de ensino: coconstrução subjetiva da capacidade de pensar o próprio pensamento em sala de aula. Rev. Bras. Psicodrama, São Paulo, v. 26, n. 1, p. 31-40, 2018.

LÉVY, P. Cibercultura. Tradução: Carlos Irineu da Costa. São Paulo: Editora 34, 2000.

MOITA LOPES, L. P. Linguística Aplicada e Vida Contemporânea: Problematização dos Construtos que Têm Orientado a Pesquisa. In: MOITA LOPES, L. P. Por uma Linguística Aplicada Indisciplinar. São Paulo: Editora Parábola, 2006. p. 85-107.

ORGANIZAÇÃO Mundial de Saúde declara pandemia do novo Coronavírus. UNA-SUS, Brasília, 11 mar. 2020. Disponível em: https://www.unasus.gov.br/noticia/organizacaomundial-de-saude-declara-pandemia-de-coronavirus. Acesso em: 20 de mar. 2020.

SANTOS, B. de S.; MENESES, M. P. (orgs.) Epistemologias do Sul. São Paulo: Editora Cortez, 2010.

SANTOS. E. O. Ambientes virtuais de aprendizagem: por autorias livre, plurais e gratuitas. Revista FAEBA, Salvador-BA, v. 12, n. 18, p. 5-25, 2003.

SCHÖN, D. Formar professores como profissionais reflexivos. In: NÓVOA, Antônio (org.). Os professores e sua formação. Lisboa: Publicações Dom Quixote, 1992. p. 79-91.

Manoela Oliveira de Souza Santana: Possui Graduação em Letras Vernáculas (Universidade do Estado da Bahia, 2001); Especialização em Mídias na Educação (Universidade Estadual do Sudoeste da Bahia, 2011); É mestra em Letras Linguagens e suas Representações (Universidade Estadual de Santa Cruz, 2013) e Doutora em Língua e Cultura (Universidade Federal da Bahia, 2019).

Orcid: https://orcid.org/0000-0002-4392-7637

Email:maneftc4@yahoo.com.br

Este periódico utiliza a licença Creative Commons Attribution 3.0, para periódicos de acesso aberto (Open Archives Initiative - OAI). 